\title{
Enhancing energy efficiency in supermarket refrigeration systems through a robust energy performance indicator
}

Salvador Acha ${ }^{\mathrm{a}}$, Yujia Du ${ }^{\mathrm{b}}$, Nilay Shah ${ }^{\mathrm{a}}$

${ }^{a}$ Centre for Process Systems Engineering, Department of Chemical Engineering, Imperial College London, London SW7 2AZ, UK

${ }^{\mathrm{b}}$ Energy Futures Lab, Imperial College London, London SW7 2AZ, UK

Email addresses: Salvador Acha (salvador.acha@ic.ac.uk) (corresponding author) (Tel: +44

(0) 7838818934), Yujia Du (yujia.du09@ic.ac.uk), Nilay Shah (n.shah@ic.ac.uk)

Key words: energy performance indicator, night blinds, pack optimisation, supermarket energy efficiency, supermarket refrigeration analysis, trading intensity.

Abstract: Supermarket chains require benchmarking and analysing refrigeration performance in order to manage their energy efficiency investments. This paper contributes in robustly assessing refrigeration system energy and carbon performance in which commonly believed drivers are used to conduct correlations. Based on this, refrigeration connected load, store opening hours and external temperature were found to construct a more representative energy performance indicator $(\mathrm{EPI})$ than other metrics. By using such an indicator, it is possible to identify poor performing systems from an estate portfolio and thus select sites suitable for energy saving measures. Furthermore, energy impact from introducing natural refrigerants is examined using empirical data from an UK supermarket chain. It was found $\mathrm{CO}_{2}$ systems have different seasonal performance than HFC systems, nonetheless on an annual basis no system has an edge over another. Lastly, other initiatives such as cabinet night blinds and suction pressure optimisation achieved $10 \%$ and $7 \%$ energy reduction respectively. 


\section{Introduction}

Supermarkets are among the most energy intensive buildings. In the UK, they are responsible for $3 \%$ of the total energy consumption and $1 \%$ of the total greenhouse gas (GHG) emissions [1]. Specifically, the refrigeration sector accounts for $30 \%$ to $60 \%$ of the total electricity use in food retail buildings and thus can be attributed a large proportion of the indirect carbon emissions. In addition, direct carbon footprint from refrigerant leakage solely accounts for about $40 \%$ of the total carbon footprint of a store, owing to the use of hydrofluorocarbons (HFC) refrigerants which have very high global warming potential (GWP) [2].

In line with the GHG emission targets set by the UK government [3], major food retailers including Asda, Tesco, Sainsbury's and Morrisons have published sustainability plans with commitments to reduce operational GHG emissions [4] [5] [6] [7]. However, a review of these reports suggests programs are mainly focused on on-site renewable generation and carbon offsetting activities, which often have higher capital investment and positive marginal abatement cost [8]. Alternatively, a much more cost effective way to mitigate carbon emissions is for these businesses to manage their energy consumption more efficiently, which has been discussed in [9] [10] [11] [12] and supported by regulations such as Carbon Reduction Commitment (CRC) Energy Efficiency Scheme and Display Energy Certificate [13] [14]. On account of the competitive environment of supermarket business, stores are often opened at a fast speed without correct commissioning, resulting in issues regarding equipment performance, energy metering and system control. This combined with a lack of energy awareness and communication among facility managers, maintenance team and store staff, makes many supermarkets perform poorly in terms of energy efficiency, which could go unnoticed for a prolonged time before being acknowledged [15] [16] [17]. This is particularly relevant for refrigeration systems, as the biggest energy user they are subject to large energy reduction potential as pointed out in [1] [2] [18] [19]. Thereby, low cost 
sustainability initiatives among supermarkets should focus more on improving the energy performance of their existing systems.

The purpose of supermarket refrigeration is to keep the temperature of the refrigerated goods at the designated level so as to slow down the rate of deterioration of perishable food or to keep cold beverages chilled [20]. A refrigeration system utilises the evaporation and condensation of refrigerants to achieve the transfer of heat from the refrigerated space (low temperature) to a heat sink (high temperature), which is normally the air outside the building [21]. Common systems utilise HFC refrigerants which are potent GHGs. However, due to the concern of climate change, natural refrigerant systems are receiving more attention in recent years [22] [23] [24] [25].

Most of the energy consumption by refrigeration systems lies on refrigeration packs (racks of compressors) and is mainly influenced by two aspects: a) the amount of heat gained in cabinets and $b$ ) the rate of heat rejected at condensers. The first one is affected by the designated cabinet temperature requirement, the rate of product replacement, cabinet aisle temperature, and indoor humidity. The second one is dependent on the surface area of the condensers, the rate of air flow and outdoor air temperature [26].

This paper focuses on different steps to achieve refrigeration energy reduction in food retail businesses, as illustrated in Fig. 1. The work begins with a characterisation of refrigeration energy demand by detailing main factors that drive it; such as opening hours and trading intensity. These factors were then analysed for correlation with refrigeration energy demand and the most relevant were chosen to construct the Energy Performance Indicator (EPI), which was then used to rank a group of stores belonging to the same supermarket chain. Thereafter, energy benefits of $\mathrm{CO}_{2}$ refrigerant systems, night blinds on refrigeration cabinets, and suction pressure optimization were studied in a test-bed store where these initiatives were applied. 
Fig.1. Steps of energy reduction planning for retail buildings.

\section{Materials and Methods}

\subsection{Test Bed Store}

In this paper, the data and analysis derived from the research focus mostly from an UK supermarket located in the south-east and referred here as the "test-bed". The store has a sales area of $35,000 \mathrm{ft}^{2}$ or $3,300 \mathrm{~m}^{2}$ and has a conventional refrigeration layout with its refrigeration plant placed in the roof and air cooled. The retailer deploys such a system with two separate packs, each using four intermediate temperature compressors and three low temperature compressors running in parallel.

The store opening hours are from 8 a.m. to 10 p.m. on weekdays and Saturday, and from 10 a.m. to 4 p.m. on Sunday. The store was opened in early 2011 and is contains multiple levels of sub-metering that has allowed us to focus in detail on the energy use of the refrigeration compressor packs. A thorough exercise was made to confirm the data captured was of good quality. Furthermore, environment data from a nearby weather station was obtained as well as sales data of the site from the commercial team of the UK retailer. Particular features of the refrigeration system in the store include:

- Transcritical $\mathrm{CO}_{2}$ refrigerant (R744) booster system with multistage compressors;

- Fully functional night-blinds in all open sales floor cabinets (chilled and frozen);

- Pack suction optimisation enabled in the refrigeration control system. 
Taken from the test-bed store, Fig. 2 presents the daily pack energy use over the course of a year while Fig. 3 illustrates a weekly energy profile at half hourly consumption rates. From Fig. 3, it can be seen that pack energy use is significantly higher during the day than at night, while Fig. 2 shows the daily energy consumption is higher during summer months (June to September) compared to the rest of the year. Usually such a large variation in energy use is owing to the fact that pack performance is highly dependent on internal and external environment of the supermarket building; such as temperature and humidity. Understanding thoroughly the dynamics that drive energy use in these systems is paramount in order to benchmark performance which can later serve to support energy conservation and efficiency programs [27].

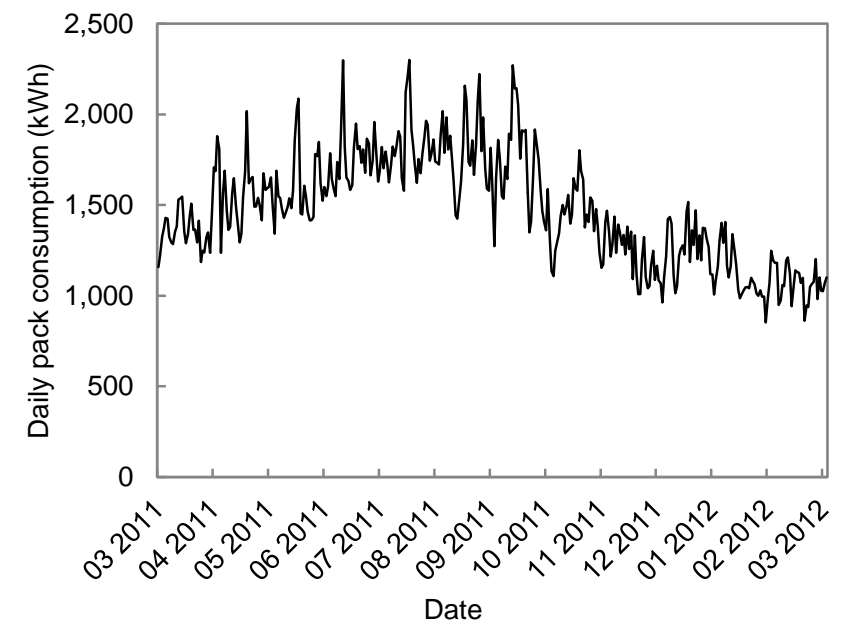

Fig.2. Daily refrigeration pack energy consumption over a year in test-bed store. Data source: J Sainsburys plc. 


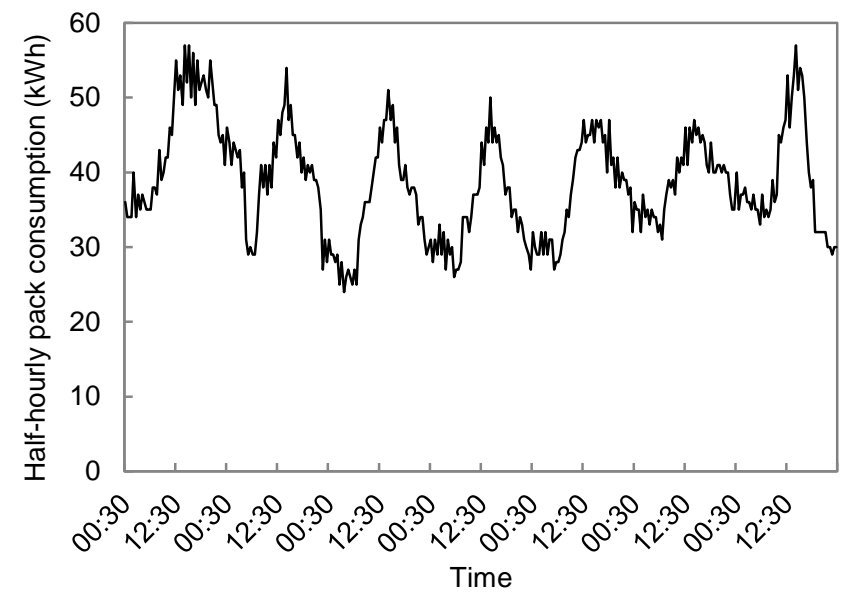

Fig.3. Half-hourly refrigeration pack energy consumption over a week in test-bed store. Data source: J Sainsburys plc.

\subsection{Energy demand characterisation}

As discussed in [2], poor performing existing buildings constitute the biggest burden of energy bills and thus carbon emissions in large supermarket chains. However, it is difficult for business to employ energy efficiency schemes across their stores due to limitation in budgets or insufficient confidence on obtaining attractive financial returns. Moreover, addressing these stores often seems to be complex and time consuming for facility managers; as they usually lack a thorough understanding of store attributes and their submetered energy use. Advocating adequate sub-metering and monitoring provide the first step in understanding energy consumption patterns. This should be followed by a straightforward and accurate method for energy comparison and performance rating to ensure that time and capital are allocated in the most effective way [16] [28] [29].

Currently, the most common indicator used to characterise energy performance in supermarkets is energy utilization indicator (EUI) i.e. total energy consumption per sales floor area (TEC/SFA), while for the refrigeration sector total energy consumption per food area $(T E C / F A)$ is often adopted [2] [28] [30]. These indicators are usually chosen because sales floor area and food area are believed to represent the size of the area dedicated to 
refrigerated cabinets, which should correspond to refrigeration energy demand. However, such an assumption has not been proven valid across businesses. Instead, employing a factor that is directly related to the refrigeration capacity would be more accurate. In this paper, the connected load (CL) was chosen. $\mathrm{CL}$ is the aggregated refrigeration load in $\mathrm{kW}$ under test conditions $\left(25^{\circ} \mathrm{C}, 60 \%\right.$ humidity $)$ in all store cabinets. To the best of our knowledge, this approach has not been applied previously thus far in the literature.

To justify the CL method a sample of 25 supermarket stores of the same company $\left(\mathrm{CO}_{2}\right.$ refrigeration sites only) were used to compare the correlation accuracy of different indicators. Historical half-hourly energy consumption data was obtained from the company's online energy monitoring system. The aggregated connected load of the refrigeration packs for each store was obtained from the engineering record database. These sites were chosen due to the availability of good quality data, as well as knowledge of in-store technology features such as on-site renewable generation and energy saving initiatives. These properties are particularly important for the analysis in the following sections. Fig. 4 shows the correlation results. It can be seen that correlation $\left(R^{2}\right)$ is enhanced $C L$ is used instead of SFA and FA, suggesting CL could be a better benchmark of refrigeration energy performance. Compared to SFA and FA, CL may not be readily available parameters for energy managers. However, it should be easily obtained by contacting facility managers or contractors.
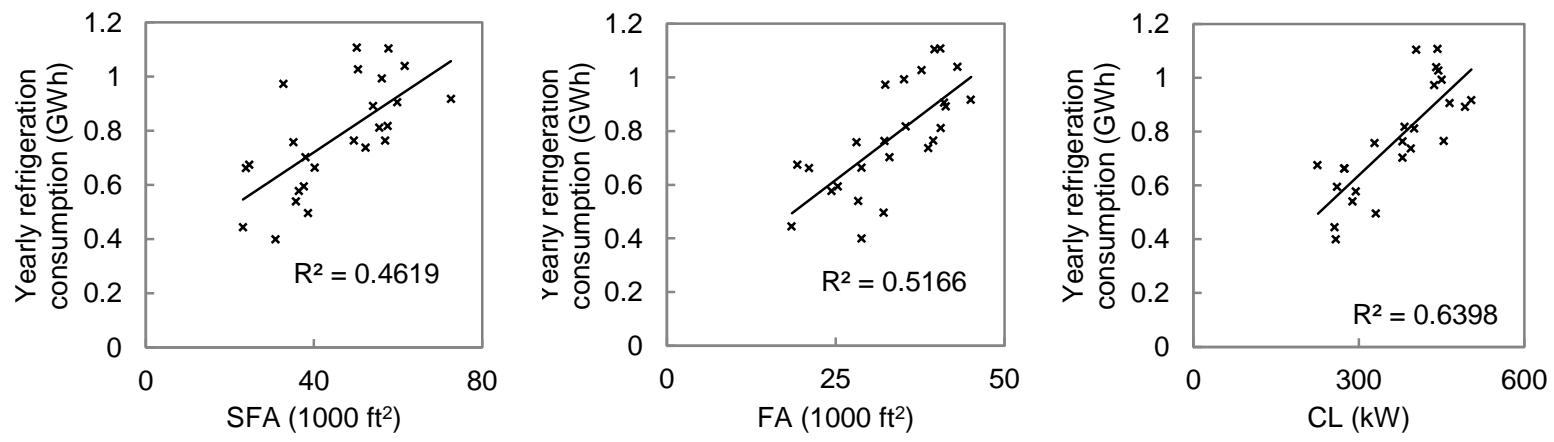

Fig.4. Yearly refrigeration energy consumption against sales floor area (SFA), food area (FA), and connected load (CL). 
As shown in Fig. 4, total energy consumption per connected load (TEC/CL) improves the analysis of refrigeration energy consumption without incorporating other influencing factors. However, for a set of stores with different trading hours, refrigeration plants, weather conditions, and building attributes, it is difficult to draw conclusions on energy performance by simply looking at TEC/CL values. A good performance indicator should allow fair energy performance comparison across store types so that inefficiencies can be identified and tackled [31]. Furthermore, a robust method should also allow for accurate energy prediction in new stores and in existing buildings upon retrofitting. To achieve a more comprehensive indicator, firstly a clear understanding of all the drivers (i.e. independent variables) of energy consumption (i.e. dependent variable) needs to be established.

Variables for interpreting refrigeration demand have been identified in the literature based on theoretical concepts, consultation with industry, and through empirical study [2] [30] [31]. Due to the attributes of these variables, Table 1 divides them into two categories: independent and dependent of which the latter is broken down into manageable and unmanageable [28]. The remainder of this section aims at developing the right indicator which incorporates these factors.

Unmanageable variables represent the physical limitations of the store which cannot be altered by engineers or energy specialists as a mean to reduce energy consumption, as listed in Table 2. For example, energy use may increase due to high outside air temperature, but this factor is not controllable and cannot be seen as a mean to save energy. It is vital to understand the impacts of unmanageable variables on energy use and they should always be held constant or normalised in order to assess the energy impact of other factors. 
Table 1. Type of variables in an energy system.

Independent variable: Electricity consumption.

Dependent variables: Factors influencing electricity consumption.

- Unmanageable dependent variables: Physical limitations of the site, uncontrollable (e.g. retail practices, building location, etc.)

- Manageable dependent variables: Controllable factors to achieve energy savings (e.g. settings changes, maintenance regimes, refurbishment programs, etc.)

Table 2. Unmanageable variables for refrigeration energy consumption.

Unmanageable variables

Trading hours: hours the store is open for business.

Trading intensity: store sales, measured in quantity of products or pounds.

Location/weather conditions: values of temperature, humidity of the location.

Store sales area/store food area: dimension allocated to merchandise display

Connected load : expected energy demand from refrigeration under test conditions

Manageable variables influence energy use due to their effect on system performance, as

shown in Table 3. These factors are technical in nature and thus can be modified by

specialists or engineers to alter refrigeration efficiency. Such variables can be further divided

into factors that can only be established when working in a new building or retrofitting a site

and those that can be conducted when the site is already functioning. Logging these

parameters in stores is needed so energy benchmarking can take place. When analysis is to

be made on system performance, ideally only one variable should be allowed to change at a

time to find its correlation with energy use - a condition that is key to reach accurate

conclusions as suggested in [31].

Table 3. Manageable variables for refrigeration energy consumption.

\begin{tabular}{ll}
\hline Manageable variables \\
\hline \multirow{2}{*}{$\begin{array}{l}\text { New build or } \\
\text { retrofits }\end{array}$} & $\begin{array}{l}\text { Refrigeration system design/Refrigerant type } \\
\text { Building type, age } \\
\text { Cabinet type, age } \\
\text { Pack size, condenser size, evaporator size }\end{array}$ \\
\hline \multirow{3}{*}{$\begin{array}{l}\text { Existing } \\
\text { working }\end{array}$} & $\begin{array}{l}\text { Refrigerant leak rate } \\
\text { buildings }\end{array}$ \\
& $\begin{array}{l}\text { Fitted doors or blinds on cabinets } \\
\text { Chilled/frozen cabinet set-point temperatures }\end{array}$ \\
& Operation, maintenance, practices
\end{tabular}




\subsection{Energy consumption indicator}

In order to develop an accurate energy performance indicator, relationships between unmanageable variables from Table 2 and energy consumption were studied. These studies were conducted using only data from a single store — the test bed store, so that the number of variables changing at the same time can be controlled. In this way, colinearity issues the distortion in correlation analysis due to the linear relationship between two independent variables can be minimised.

\subsubsection{Impact of opening hours}

Firstly, impact on energy from opening hours was studied. Half-hourly refrigeration pack energy data over a whole year was used to find out the average hourly consumption throughout the day for weekdays and Sundays respectively, as seen in Fig. 5 and 6. Sunday data was plotted separately due to shorter opening hours. It can be seen that during trading hours, energy consumption is significantly higher when compared to non-trading hours. One of the main reasons for this is the higher external temperature during daytime compared to night-time. However, the sharp changes around opening and closing hours imply that in-door conditions also influence energy use, supported by the different energy use pattern on Sundays. This sharp drop in energy can be explained by changes in store temperature due to relaxed heating, ventilating, and air conditioning (HVAC) settings, reduced heat radiation exerted from sales floor lighting, and lower occupancy levels when store is closed. This argument is supported by the fact that in-door store temperature when trading is set at $19^{\circ} \mathrm{C}$, while the same space when the store is closed is kept at $16^{\circ} \mathrm{C}$. Consequently, in this paper it is assumed that refrigeration pack energy consumption increases with longer opening hours. By comparing energy use between Monday-Saturday data and Sunday data, an expected change in energy pack consumption due to one extra hour of trading can be expressed in the following manner: 


$$
\Delta E(\%)=\frac{E_{m-s}-E_{s}}{H_{m-s}-H_{s}} \times \frac{1}{E_{m-s}}
$$

where:

- $\Delta E(\%)$ is the percentage change in pack energy due to one extra hour of trading

- $E_{m-s}(\mathrm{kWh})$ is the average daily pack energy consumption between Monday and Saturday

- $E_{S}(\mathrm{kWh})$ is the average daily pack energy consumption on Sunday

- $H_{m-s}$ is the number of hours the store is trading between Monday and Saturday

- $H_{S}$ is the number of hours the store is trading on Sunday

Using the values obtained from Fig.5 and 6, it was found that for each extra hour of trading, on average $0.94 \%$ additional energy is consumed by the refrigeration packs.

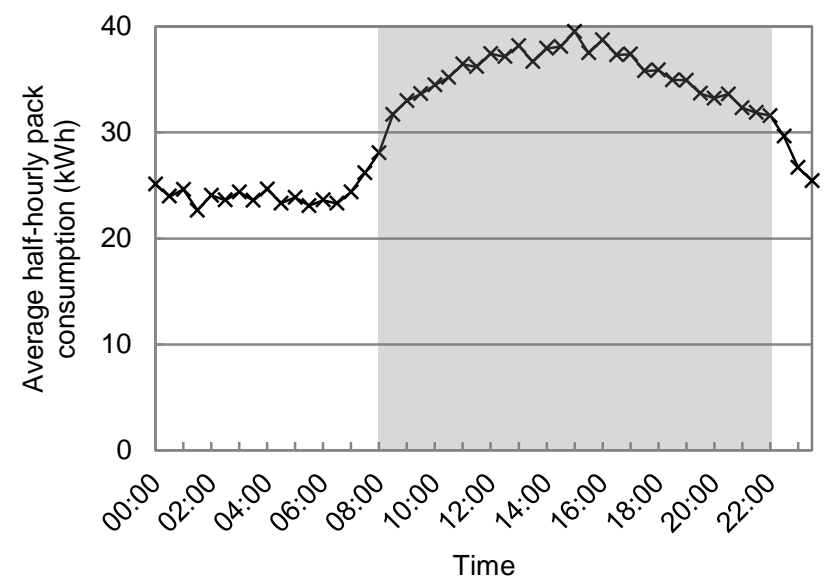

Fig.5. Average half-hourly refrigeration pack energy consumption in test-bed store from Monday to Saturday; shaded area indicates store opening hours. 


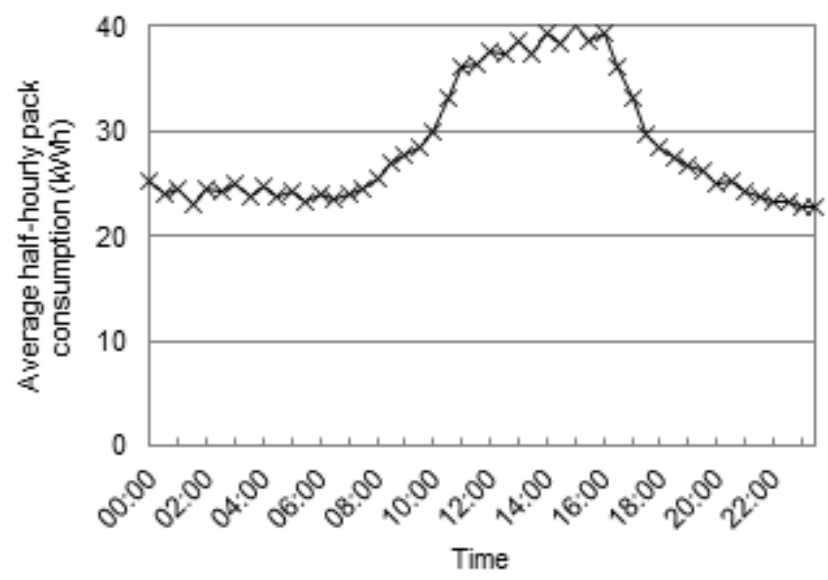

Fig.6. Average half-hourly refrigeration pack energy consumption in test-bed store for Sundays; shaded area indicates store opening hours.

\subsubsection{Trading intensity impact}

Another factor that is commonly believed to affect energy consumption is trading intensity, measured by total revenue of products sold. Higher trading intensity is believed to lead to higher energy consumption due to the extra heat load exerted on door less cabinets from customers, accompanied by a higher rate of food replacement. To examine this phenomenon, trading patterns were studied using sales (measured in revenue) data coupled with the energy data period employed in the previous section. Fig. 7 is the normalised average daily sales of refrigeration products (frozen, chilled and fresh food) and average hourly sales of these products for each day of the week. It can be seen that daily and hourly sales are relatively constant between Monday and Wednesday and then increase from Thursday till the weekend. This portrays the change in shopping intensity throughout the week. Average hourly sales continue to grow till Sunday while average daily sales drop significantly (because of the shorter trading period). Based on this, a more detailed analysis of the sales trend was conducted. Fig. 8 illustrates trading intensity throughout the trading periods for different days of the week. It can be seen that most of the sales occur between 10 a.m. to 6 p.m. throughout the week and then drop sharply after 6 p.m. Nevertheless, 
energy use remains relatively high until store closes at 10 p.m., as shown in Fig. 5 . This revelation suggests a trade-off study comparing sales and energy costs could be valuable in deciding opening hours of stores if operating costs become too expensive. It is worth noting that the test-bed store is located in the centre of a small-size town; hence the trading pattern shown here is representative for supermarkets in similar areas across the UK.

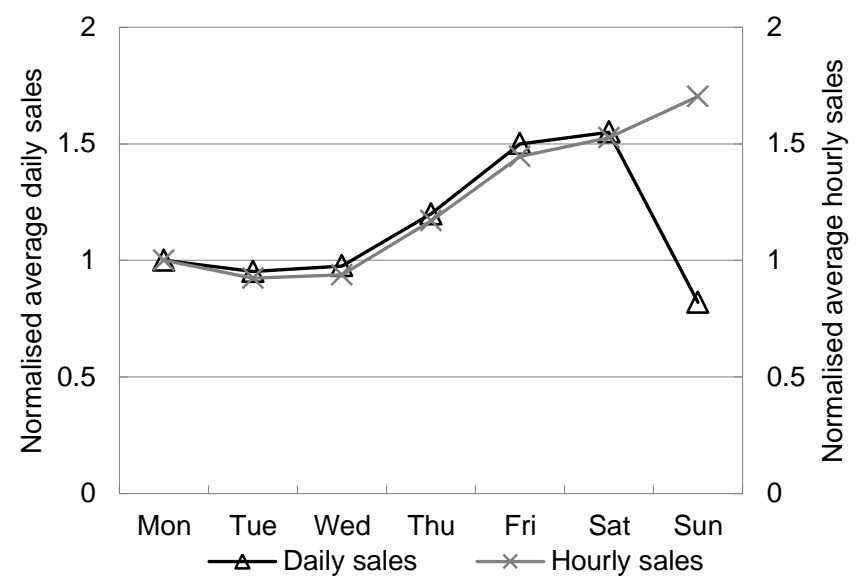

Fig.7. Average daily and hourly sales of refrigerated goods in test-bed store over a weekly period.

Values are normalised against Mondays.

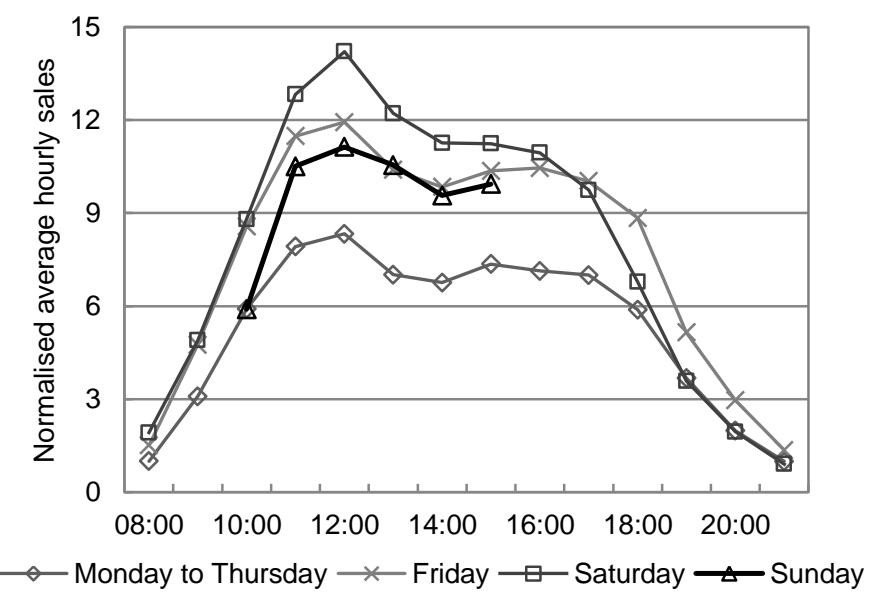

Fig.8. Average hourly sales of refrigerated goods in test-bed store per hour for Monday to Thursday, Friday, Saturday and Sunday. Values are normalised against Monday to Thursday between 8:00 a.m. and 10:00 p.m. 
To find the relationship between energy demand and trading intensity, average daily pack consumption and average daily sales are plotted for each day of the week as shown in Fig. 9. By using average data for each day, influence from other variables such as temperature can be eliminated. It can be seen from this figure that unlike what is commonly believed, pack consumption is not influenced by sales [30]. While trading intensity increases dramatically towards the end of a week, daily pack energy consumption fluctuates steadily around 1,500 kWh (except for a drop on Sundays which is attributed to shorter opening hours instead of changes in sales). Thus, in this paper, trading intensity is assumed to have negligible influence on refrigeration energy consumption and therefore it was not included in the development of the energy intensity indicator explained later in this paper.

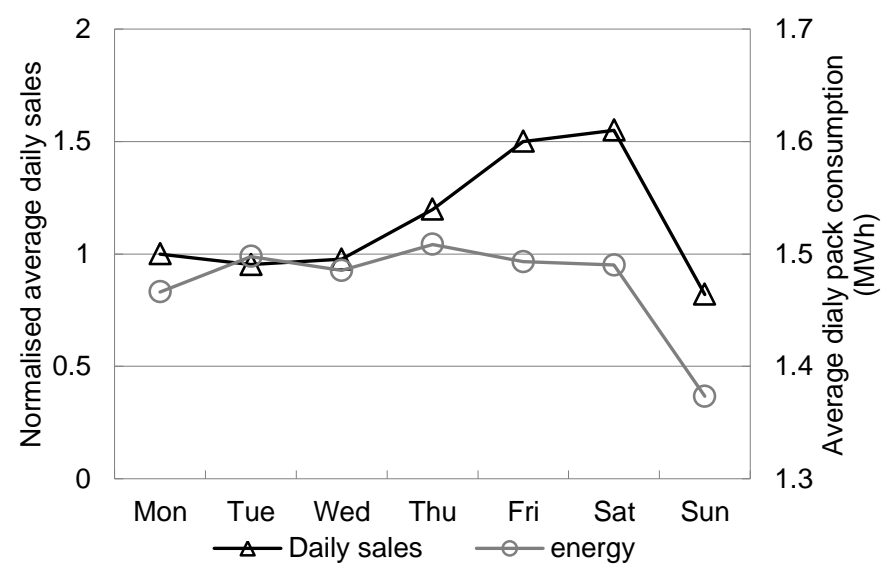

Fig.9. Average daily sales of refrigerated goods over a weekly period and average daily pack energy consumption in test-bed store. Values for sales are normalised against Mondays.

\subsubsection{Impact of Outside Air Temperature}

Fig. 10 shows daily pack energy demand against average outside air temperature. It can be seen that the correlation between them is very strong. This can be explained by the fact that 
higher outside temperature requires higher condensing temperatures, therefore exerting more work on compressor packs. Such a strong relationship indicates that for supermarket refrigeration system similar to the test-bed's, given other factors stay the same, energy prediction throughout the year can be achieved quite effectively using mostly weather data. Such predictions can be particularly useful for energy procurement and evaluation or when new stores are being designed as stated in research concerning forecasting demand [32].

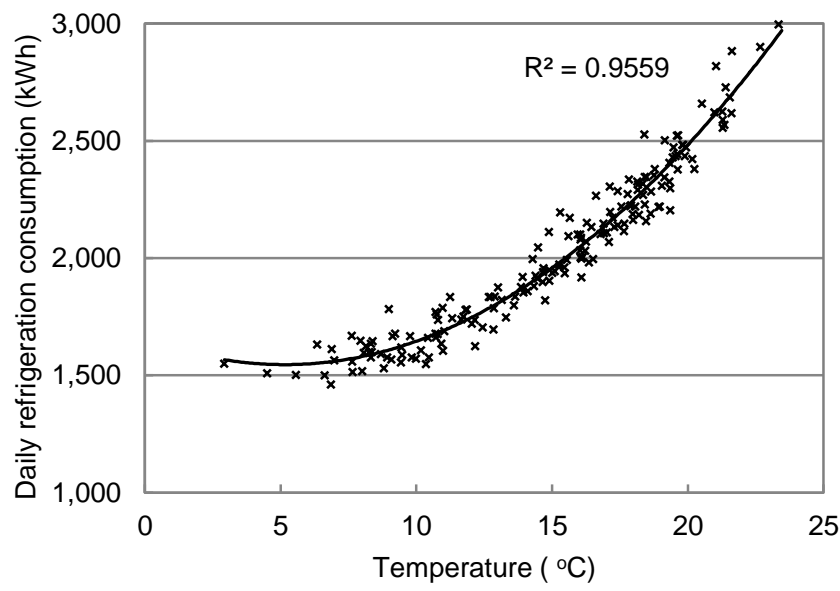

Fig.10. Daily refrigeration pack energy consumption against outside air temperature in test-bed store.

As weather conditions strongly influence pack energy consumption, weather correction is crucial when comparing store energy use at different locations and during different time periods. Polynomial regression was applied between daily cooling degree days (CDD) and daily total refrigeration energy use. CDD data from a local weather station was chosen to represent external temperature using a base temperature of $-10^{\circ} \mathrm{C}$ [33]. Such a low base temperature was purposely selected because unlike space heating and cooling demand, refrigeration packs consumes energy throughout the year. Using CDD instead of temperature also ensures consistency for analysis in later sections. Similarly, total refrigeration energy consumption was selected to replace total pack energy because the 
later one is not available in most stores due to the lack of energy sub-metering. Compared to pack energy data, total refrigeration data also includes a small amount of energy consumed by cabinet lighting, defrost heaters and anti-sweat heaters. A full year of CDD data was applied to equation (2) and (3) to obtain the expected yearly energy use; results were compared to actual values as shown in Fig. 11. By varying average daily CDD, it was found that for each degree change in CDD, a $2.8 \%$ change in energy consumption is expected from the refrigeration system. Noting for the simplicity of this study, the relationship between energy consumption and average temperature is assumed to be linear. This assumption is based on the fact that average temperature in Britain is within a few degrees difference from the test-bed store [34]. Lastly, it is worth reminding that the test-bed store has a $\mathrm{CO}_{2}$ refrigerant system; hence the consumption/CDD relationship may vary for systems employing other refrigerants, such as R404A.

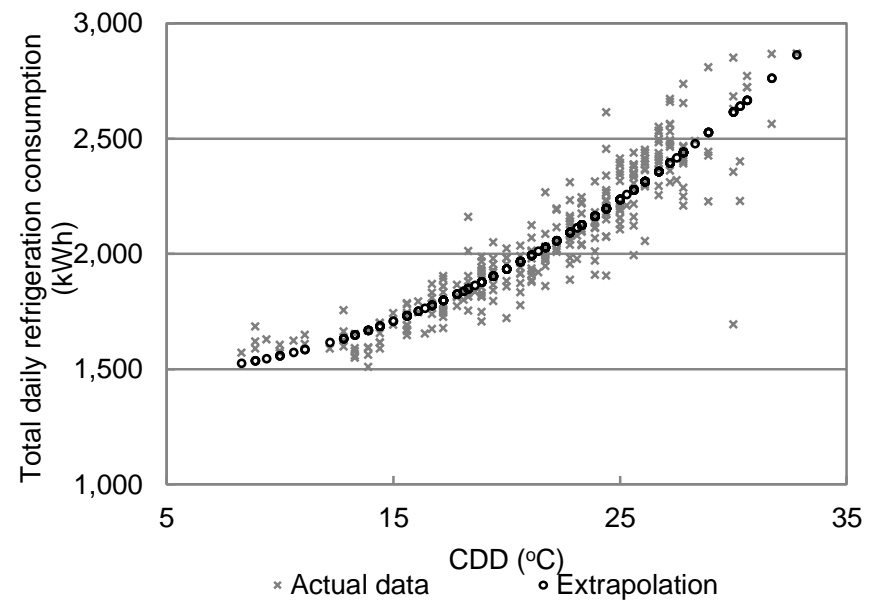

Fig.11. Actual and modelled total daily refrigeration energy consumption against cooling degree day for test-bed store. 


\subsection{Energy performance indicator}

Based on the analysis above, an energy consumption indicator was developed incorporating parameters such as connected load, opening hours and CDD. Total refrigeration energy use over a year was normalised in equation (4) by calculating the energy consumption factor $C_{x}$ for store :

$$
C_{x}=\frac{E_{A, x}}{C L_{x} \times\left\{1+\left(H_{T, x}-14\right) \times 0.94 \%\right\} \times\left\{1+\left(C D D_{x}-20.1\right) \times 2.8 \%\right\}}
$$

Where $E_{A, x}(\mathrm{kWh})$ represents annual refrigeration consumption and is normalized by:

- $C L_{x}(\mathrm{~kW})$, the aggregated connected load of the refrigeration system.

- $\left\{1+\left(H_{T, x}-14\right) \times 0.94 \%\right\}$ the normalisation for opening hours, where $H_{T, x}$ is weekday trading hours for store $x$ and 14 is weekday trading hours at test-bed store.

- $\left\{1+\left(C D D_{x}-20.1\right) \times 2.8 \%\right\}$, the normalisation of $C D D$, where $C D D_{x}$ is annual average CDD and 20.1 is the annual average CDD at the test-bed store.

- Note: weekday factors are only presented in this equation

The energy consumption indicator $\boldsymbol{I}_{\boldsymbol{x}}$ is obtained by comparing $C_{x}$ for store $x$ against the same value from test-bed store $C_{\text {test }}$; as equation 4 details:

$$
I_{x}=\frac{C_{x}}{C_{\text {test }}}
$$

By using the above equation, the annual refrigeration energy consumption is normalised based on the connected load, trading hours and average external CDD of the store. 


\section{Applications of EPI}

\subsection{Performance ranking}

Using the energy performance indicator developed, a group of 24 stores (of the same supermarket chain) were ranked based on their refrigeration energy performance using data for a full year. It was found that most stores score higher than the test-bed store, suggesting they are less energy efficient. On average, stores score 1.17, meaning they use relatively 17\% more energy. To better visualise the results, Fig. 12 illustrate EPI values plotted against store size for different stores. In these figures bubble size represents absolute annual refrigeration energy consumption, light grey signifies $\mathrm{CO}_{2}$ stores and dark grey bubbles are HFC stores. It can be seen that the worst performing stores, located at the top of the graph, use more than $70 \%$ energy in terms of refrigeration than the test bed store $(E P I=1)$. These results suggest that large energy savings can be achieved if further investigation is conducted in these stores. On the other hand, there exist several stores at the bottom of the graph, with even better refrigeration performance than the test-bed store. By investigating these stores, best design and operation learning's can be identified and therefore reenforced at other stores. Furthermore, it also appears that $\mathrm{CO}_{2}$ stores score lower than $\mathrm{HFC}$ stores in general. The main reason for this pattern is that for the supermarket chain studied, their $\mathrm{CO}_{2}$ stores tend to be newer stores compared to HFC stores; hence benefitting from more recent equipment and enhanced energy saving features. Further investigation into store types will be discussed in section 4. 


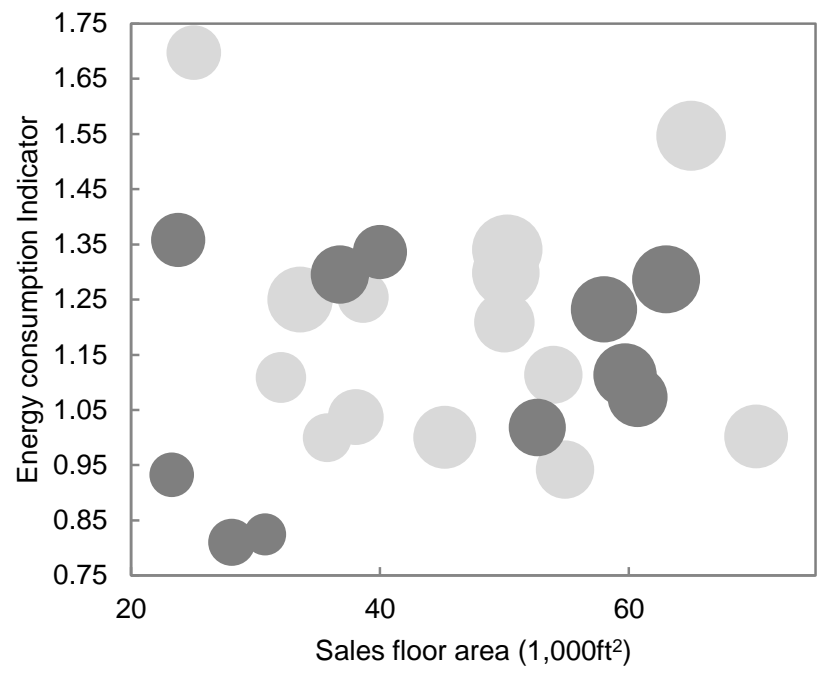

Fig.12. EPI against sales floor area for HFC stores (light grey) and $\mathrm{CO}_{2}$ stores (dark grey). Bubble size represents absolute annual energy use.

Similarly, Fig. 13 illustrates the EPI against sales floor area where bubble size represents absolute carbon emissions. Absolute emissions consist of both direct carbon emissions from refrigerant leakage and indirect carbon emissions from electricity use. The former one is deducted from the total amount of refrigerant top-up required during the year assessed. By looking at the bubble size, it is evident that $\mathrm{CO}_{2}$ stores produce a lot less carbon emissions compared to HFC stores, as a result of the large difference in refrigerants' GWP. R404A refrigerant has a global warming potential 3,260 times higher than $\mathrm{CO}_{2}$, hence even small amount of leakage results in a large amount of direct carbon emissions [35]. 


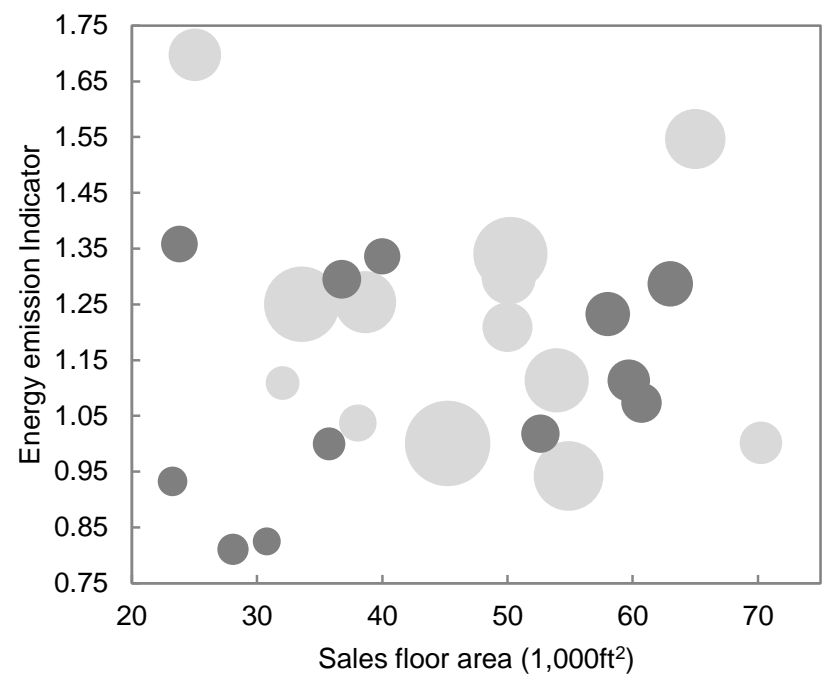

Fig.13. EPI against sales floor area for HFC stores (light grey) and CO2 stores (dark grey). Bubble size represents absolute annual CO2e.

\subsection{Refrigeration energy initiatives evaluation}

The indicator developed in this paper allows engineers to conduct a more fair energy comparison across stores by considering 3 unmanageable variables: refrigeration load, opening hours and weather conditions. After the identification of candidate stores of poor performance, energy saving initiatives, which are mainly the adjustment of manageable variables, can be applied in order to improve their energy efficiency. In this section, three such initiatives are studied to find out their impact on store energy consumption. They are refrigeration system type, the use of cabinet night blinds, and suction pressure optimisation.

\subsubsection{Refrigeration system analysis: $\mathrm{CO}_{2}$ versus HFC}

As a mean to reduce the business's total carbon emissions, the supermarket chain committed shifting to systems running on $\mathrm{CO}_{2}$ refrigerant for all their new buildings as of 2009 [36]. On top of apparent carbon savings due to the lowered GWP, in this section, the energy performance of these systems is studied. As discussed in Section 3.3, $\mathrm{CO}_{2}$ stores appear to have lower EPI values than HFC stores. One of the main arguments for this is that 
$\mathrm{CO}_{2}$ refrigeration systems tend to be installed only in new or refurbished buildings, which are likely to have more energy efficient equipment compared to older HFC stores. A closer look into their performance against daily CDD reveals how these two types of systems perform under different climate conditions. Based on the EPI developed in this study, annual refrigeration energy consumption for a group of $\mathrm{CO}_{2}$ and $\mathrm{HFC}$ stores were normalised by connected load and opening hours, which is plotted against CDD, as seen in Fig. 14. Only trend lines for different stores are shown to emphasize the correlation. It can be seen that when compared to $\mathrm{CO}_{2}$ stores, most HFC stores have higher energy consumption for low CDD values; however this trend is reversed for values higher than $20 \mathrm{CDD}$ and thus $\mathrm{CO}_{2}$ stores use more energy. This trend can be explained by deteriorating efficiency as external temperature gets closer to the critical $32^{\circ} \mathrm{C}$ temperature of $\mathrm{CO}_{2}$, above which the refrigerant cannot dump heat via condensation. This suggests $\mathrm{CO}_{2}$ stores are more energy efficient in colder locations, as advocated by specialists in multiple publications [22] [23] [24].

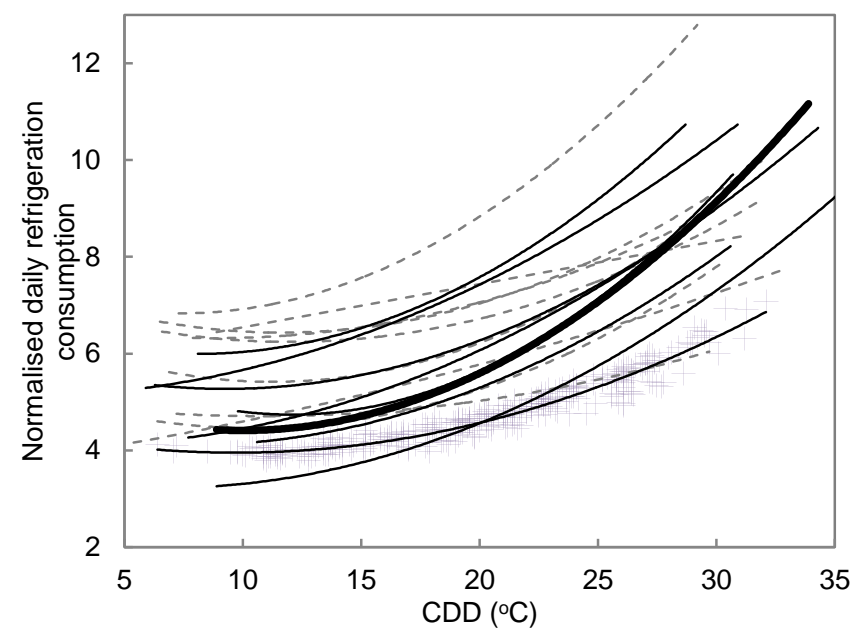

Fig. 14. Normalised daily refrigeration consumption against daily CDD for 8 HFC stores (grey, dotted) and $8 \mathrm{CO}_{2}$ stores (black, solid); the dark solid line represents the test-bed store. 


\subsubsection{Impact of night blinds and suction pressure optimisation}

In the test-bed store, cabinet night blinds were installed before store opening. They are roller blinds which can be pulled down during non-trading hours to reduce warm air infiltration; hence reducing energy consumed on refrigeration packs. This measure was introduced as a compromise between energy conservation and impact on shopping experience, instead of installing glass doors. Despite not having an influence on customers, night blind use may have a negative impact on replenishing refrigerated items inside cabinets during non-trading hours. Therefore, staff are not likely to pull down night blinds when store closes, thus making energy saving very limited. During the store's first year of business, a night blind use culture was non-existent, however at the start of its second year a night blind engagement programme was applied to encourage participation. Staff received awareness training and optimised replenishing strategy to ensure they understand the importance of energy saving. In addition, weekly participation rate was monitored and reported back to the store manager in order to maintain engagement.

Additionally, a few months later, suction pressure optimisation was also implemented at the site. This refers to floating the suction pressure to reduce energy on compressors while maintaining adequate product temperature [37]. The authors conducted an analysis to evaluate both initiatives as the test-bed store possesses sub-monitoring capability.

Fig. 15 shows daily pack energy use for three different operating conditions:

- $B A U$ is the first year of business where no refrigeration energy initiatives were applied, i.e. business as usual (BAU).

- Blinds represents the time from when night blinds engagement was introduced until suction pressure optimisation was implemented.

- Blinds+Po scenario covers the period when suction pressure optimisation (Po) was activated in conjunction with night blind use. 
It can be seen from Fig. 15 that energy use is lower for a given CDD in the latter two scenarios; indicating refrigeration pack consumption is reduced. By extrapolating this trend to a whole year of CDD data, it was found that $10 \%$ of total pack energy can be saved by using night blinds; together with optimisation this number becomes $17 \%$. Summary of the savings obtained from more efficient operation is shown in Table 4. In terms of EPI the testbed store in its first year of business scored 1.15 as opposed to 1 in its second year of operation. This suggests refrigeration energy performance can be improved significantly by introducing the use of night blinds and suction pressure optimisation. Due to their attractive savings, food retailers would be wise to actively support such energy efficiency initiatives, especially as it appears most cabinets and packs manufacturers can easily incorporate these attributes as standard features in their current portfolio of services.

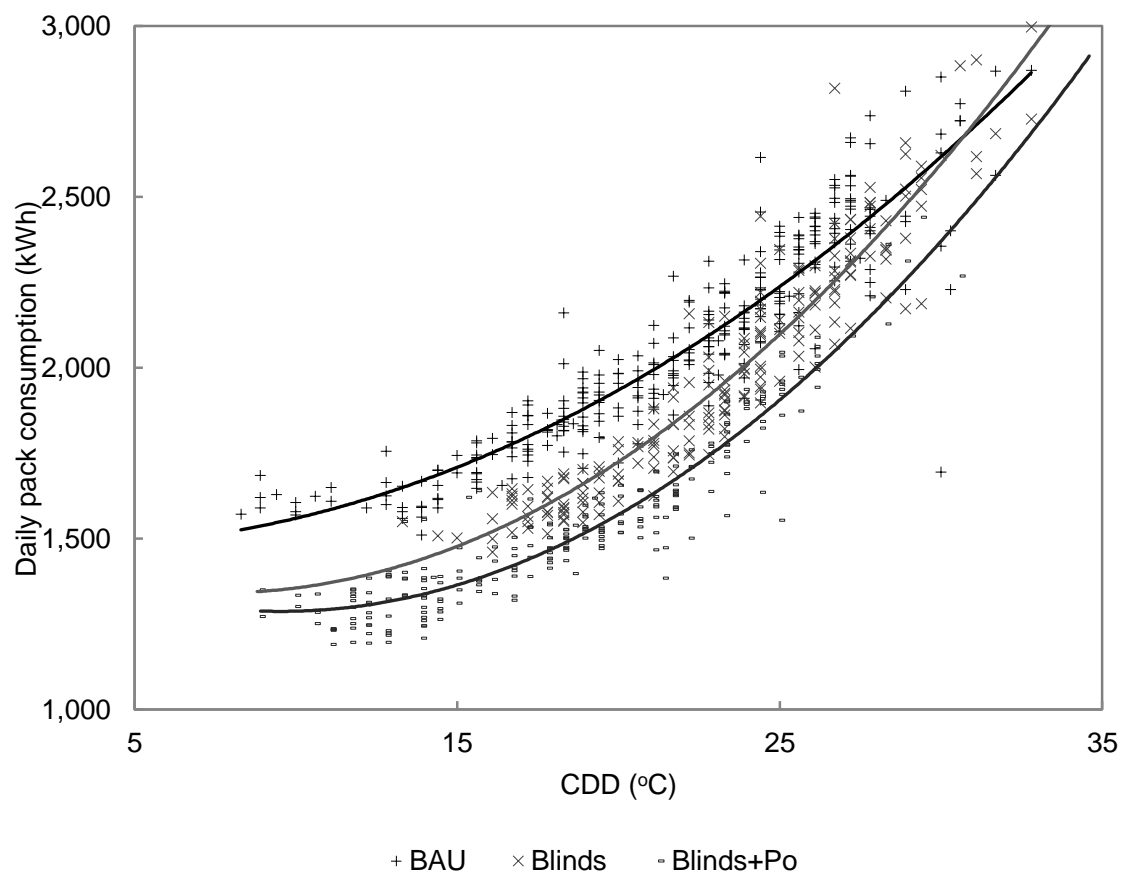

Fig.15. Daily refrigeration pack energy consumption comparison for three different operating conditions at the test-bed store: business as usual (BAU), night blinds on cabinets during non-trading times only (Blinds), and night blinds on cabinets with pack optimisation (Blinds+Po). 
Table 4. Energy, cost and CO2 savings for scenarios Blinds and Blinds+Po compared to scenario $\mathrm{BAU}$ at test-bed store.

\begin{tabular}{cccc}
\hline & BAU & Blinds & Blinds+Po \\
\hline Yearly energy usage (kWh) & 716,673 & 646,514 & 593,343 \\
Energy saved/total packs use & - & $9.8 \%$ & $17.2 \%$ \\
Energy saved/total store electricity use & - & $4.5 \%$ & $7.9 \%$ \\
Yearly cost saved & - & $\$ 11,100$ & $\$ 19,500$ \\
Yearly CO 2 saved (tonne) & - & 36.5 & 64.1 \\
Payback period & & 6 months & 3 months for Po only \\
\hline
\end{tabular}

\section{Conclusions and further work}

Supermarkets are among the most energy intensive buildings and in particular the refrigeration systems installed in these sites as they have the main goal of keeping perishable foods in a good state. Nonetheless, it is very important for food retailers to improve efficiency performance of their refrigeration systems so they can adequately target assets in poor conditions. This paper has focused on presenting a sound framework to adequately analyse and compare refrigeration system performance by introducing a novel energy performance indicator.

The most relevant factors influencing refrigeration demand were identified to be: connected pack load, store opening hours and CDD. These factors allowed us to construct the EPI, which was then used to rank a group of stores belonging to the same supermarket chain. Thereafter, energy benefits of $\mathrm{CO}_{2}$ refrigerant systems, night blinds on refrigeration cabinets, and suction pressure optimization were studied in a test-bed store where these initiatives were applied.

It was found that for every extra opening hour in a supermarket, there is a $0.94 \%$ increase on refrigeration pack energy use. Similarly, for every degree increase in external temperature, there is a $2.8 \%$ rise in energy refrigeration consumption. In addition, unlike what is commonly believed, no correlation between trading intensity and refrigeration demand was found. Compared to HFC systems, it was found that energy consumption 
increases faster in $\mathrm{CO}_{2}$ stores in higher cooling degree days. The opposite trend was found during lower CDD values. Two energy saving initiatives were investigated. By pulling down night blinds on refrigerated cabinets during non-trading hours, at least $10 \%$ energy from refrigeration can be saved over a year. Combined with suction pressure optimisation, a further $7 \%$ energy reduction can be achieved. If such measures were transferred and applied by food retailers to the rest of the building portfolio important benefits could come about in terms of energy cost reduction and carbon mitigation.

Although the EPI presented is a step forward in energy analysis of system performance, the accuracy of its equation and subsequent conclusions are dependent on the quality of the input energy and weather data; an issue that could still be improved further. Due to the limitation of data availability, in this paper, only the test-bed store was used to develop the parameters in the EPI equation, which should be repeated with many more stores to improve precision. More work should also be done to justify relationship between refrigeration energy consumption and other factors, such as humidity and building types [38]. If proven that significant correlation exists, such parameters should be included into the enhanced EPI. Lastly, the proposed methodology for a more insightful EPI could also be transferred to assess other energy systems such as HVAC and lighting systems; researching data parameter availability and assessing correlations would translate into a better performance assessment of such systems.

\section{Acknowledgments}

The research was supported by funds provided via the Imperial College London $-\mathrm{J}$ Sainsburys plc partnership. 


\section{References}

[1] The Carbon Trust, "Refrigeration Road Map," The Carbon Trust, 2010.

[2] S.A.Tassou, Y.Ge, A. Hadawey and D.Marriott, "Energy consumption and conservation in food retailing," Applied Thermal Engineering, vol. 31, no. 2-3, p. 147-156, 2011.

[3] Department of Energy \& Climate Change, Committee on Climate Change, Department for Environment, Food \& Rural Affairs and Department for Transport, "Reducing the UK's greenhouse gas emissions by $80 \%$ by 2050," GOV.UK, 136 2013. [Online]. Available: https://www.gov.uk/government/policies/reducing-the-uk-s-greenhouse-gas-emissions-by-80by-2050. [Accessed 1311 2013].

[4] Asda Stores Limited, "Sustainability 2.0, Asda's Environmental Sustainability Targets 20102015," 282 2012. [Online]. Available: http://your.asda.com/system/dragonfly/production/2012/02/28/09_37_08_670_10_10_26_48 8_Asda_2_0_Sustainability_Strategy_updated.pdf. [Accessed 259 2013].

[5] T. PLC, "Tesco and Society Report 2013," 2013. [Online]. Available: http://www.tescoplc.com/files/pdf/reports/tesco_and_society_2013_ipad.pdf. [Accessed 68 2013].

[6] J Sainsbury plc, "20x20 Sustainability Plan," 11 2012. [Online]. Available: http://www.jsainsbury.co.uk/media/1377005/jsainsbury_20x20_sustainability_brochure.pdf. [Accessed 68 2013].

[7] Wm Morrison Supermarkets PLC, "Today taking good care for tomorrow, Corporate Responsibility Review 2010/2011," 2011. [Online]. Available: http://www.morrisons.co.uk/Documents/Morrisons_Corporate_Responsibility_Review_2011.p df. [Accessed 259 2013].

[8] V. Caritte, S. Acha and N. Shah, "Enhancing Corporate Environmental Performance Through Reporting and Roadmaps," Business Strategy and the Environment, 2013.

[9] L. Perez-Lombard, J. Ortiz and C. Pout, "A review on buildings energy consumption information.," Energy and buildings, vol. 40, no. 3, pp. 394-398, 2008.

[10] H. Geller, A. H. Philip Harrington, S. T. Rosenfeld and F. Unander, "Polices for increasing energy efficiency: Thirty years of experience in OECD countries.," Energy Policy, vol. 34, no. 5, pp. 556$573,2006$.

[11] E. Mills, "Building Commissioning: A Golden Opportunity for Reducing Energy Costs and Greenhouse-gas Emissions.," Berkeley, 2010.

[12] J. Laustsen, "Energy efficiency requirements in building codes, energy efficiency policies for 
new buildings.," International Energy Agency (IEA), 2008.

[13] Environmental Agency, "CRC Energy Efficiency Scheme," Department of Energy \& Climate Change, 237 2013. [Online]. Available: https://www.gov.uk/crc-energy-efficiency-scheme. [Accessed 1111 2013].

[14] Department of Energy \& Climate Change, "Display energy certificate," 73 2011. [Online]. Available: https://www.gov.uk/government/uploads/system/uploads/attachment_data/file/48037/1355decc-display-energy-certificate-dec.pdf. [Accessed 1111 2013].

[15] S. Acha, G. Mavromatidis, V. Caritte and N. Shah, "Effective Low-cost Energy Saving Strategies in Supermarkets: An UK Case Study.," in ECOS 2013, Guilin, 2013.

[16] G. Escrivá-Escrivá, "Basic actions to improve energy efficiency in commercial buildings in operation.," Energy and Buildings, vol. 43, no. 11, pp. 3106-3111, 2011.

[17] The Carbon Trust, "Making buildings work-Lessons learned from commissioning low carbon buildings," The Carbon Trust, London, 2012.

[18] A. D. Little, "Energy savings potential for commercial refrigeration equipment.," Building Equipment Division Office of Building Technologies U.S. Department of Energy, Cambridge, 1996.

[19] A. Bahman, R. Luis and M. R. Muhammad, "Analysis of energy savings in a supermarket refrigeration/HVAC system.," Applied Energy, vol. 98, pp. 11-21, 2012.

[20] Food Standards Agency, "Guidance on Temperature Control Legislation in the United Kingdom," Food Standards Agency, 2007.

[21] D. Westphalen, R. Zogg, A. Varone and M. Foran, "Energy Savings Potential for Commercial Refrigeration Equipment," U.S. Department of Energy, Cambridge, 1996.

[22] L. Cecchinato, M. Corradi and S. Minetto, "Energy performance of supermarket refrigeration and air conditioning integrated systems working with natural refrigerants," Applied Thermal Engineering, vol. 48, p. 378-391, 2012.

[23] S. Sawalha, "Theoretical evaluation of trans-critical CO2 systems in supermarket refrigeration. Part II: System modifications and comparisons of different solutions," International Journal of Refrigeration, vol. 31, no. 1, p. 525-534, 2008.

[24] P. Bansal, "A review - Status of $\mathrm{CO} 2$ as a low temperature refrigerant: Fundamentals and R\&D opportunities," Applied Thermal Engineering, vol. 41, pp. 18-29, 2012.

[25] I. Suamir, S. Tassou and D. Marriott, "Integration of CO2 refrigeration and trigeneration systems for energy and GHG emission savings in supermarkets," International Journal of Refrigeration, 
vol. 35 , no. 2, p. 407-417, 2012.

[26] The Food and Drink Federation, "Food \& Drink Industry Refrigeration Efficiency Initiative- Site Guidance Topics," The Carbon Trust , 1007.

[27] The Carbon Trust, "Refrigeration systems-Guide to key energy saving opportunities," The Carbon Trust, London, 2011.

[28] W. Chung, Y. Hui and Y. Lam, "Benchmarking the energy efficiency of commercial buildings," Applied Energy, vol. 83, no. 1, pp. 1-14, 2006.

[29] G. Escrivá-Escrivá, C. Álvarez-Be and E. Peñalvo-López, "New indices to assess building energy efficiency at the use stage," Energy and Buildings, vol. 43, no. 2-3, p. 476-484, 2011.

[30] M. S. Spyrou, K. Shanks, M. J. Cook, J. Pitcher and R. Lee, "An empirical study of electricity and gas demand drivers in large food retail buildings of a national organisation," Energy and Buildings, vol. 68, p. 172-182, 2014.

[31] M. B. J.Kenneth Monts, "Assessing energy efficiency and energy conservation potential among commercial buildings: A statistical approach," Energy, vol. 7, no. 10, p. 861-869, 1982.

[32] G. Mavromatidis, S. Acha and N. Shah, "Diagnostic tools of energy performance for supermarkets using Artificial Neural Network algorithms," Energy and Buildings, vol. 62, p. 304314, 2013.

[33] “Degree Days," BizEE Software Limited, 2013. [Online]. Available: http://www.degreedays.net/. [Accessed 1211 2013].

[34] "UK Climate, Location Comparision," Met Office, [Online]. Available: http://www.metoffice.gov.uk/public/weather/climate/london-greaterlondon\#?tab=climateComparisons. [Accessed 411 2013].

[35] N. Hill, H. Venfield, C. Dun and K. James, "2013 Government GHG Conversion Factors for Company Reporting: Methodology Paper for Emission Factors," Department for Environment, Food and Rural Affairs, London, 2013.

[36] J Sainsburys plc, "Sainsbury's accelerates green refrigeration programme," J Sainsburys plc, 162 2012. [Online]. Available: http://www.j-sainsbury.co.uk/media/latest-stories/2012/20120216sainsburys-accelerates-green-refrigeration-programme/. [Accessed 281 2014].

[37] Danfoss, Food Retail refrigeration - Natural refrigerants with adaptive suction pressure control, danfoss.

[38] IEA/OECD, Legal Text for Annex 44. "Performance indicators for energy efficient supermarket buildings". [Online]. Available: http://www.nightwind.eu/mediapool/48/485045/data/Legal_Text_Annex_44__Performance_Indicators_for_Energy_Efficient_Supermarket_Bui.pdf [Accessed 0810 2015]. 
